Cloning of ProAV promoter isolated ... (Andi Parenrengi)

\title{
CLONING OF PROAV PROMOTER ISOLATED FROM TIGER PRAWN Penaeus monodon
}

\author{
Andi Parenrengi*)\#, Alimuddin**), Sukenda*), Komar Sumantadinata**), \\ Muhammad Yamin*), and Andi Tenriulo*) \\ ${ }^{*}$ Research Institute for Coastal Aquaculture, Maros, South Sulawesi 90511, Indonesia \\ ${ }^{*}$ Department of Aquaculture, Faculty of Fisheries and Marine Science, \\ Bogor Agricultural University, Bogor
}

\begin{abstract}
Promoter is a specific DNA sequence involved in the transcription of a particular gene. It is usually located in the upstream of the gene they regulate. Isolation and characterization of promoter is essentially needed in order to establish the sequence analysis and transcription factor that are used in the regulation of gene expression. The research was conducted to analyze the characteristics of Penaeus monodon anti viral gene promoter (ProAV) towards generation of auto- transgenic tiger prawn, $\mathrm{P}$. monodon. ProAV promoter_was isolated by PCR (Polymerase Chain Reaction) method and the purified DNA fragment was cloned into pGEM-T Easy cloning vector. The promoter sequence was characterized by using BLAST- N and Genetyx version 7 softwares. The results showed the success in isolating a promoter from tiger prawn of 368_bp in length. BLAST- $\mathrm{N}$ analysis showed that the sequence of isolated promoter has high similarity (95\% 98\%) compared to the other promoters in the GeneBank. The study revealed the existence of important transcription factors (TATA box, MRE, TCF1 , and other potential regulatory elements) are identified in the promoter sequence.
\end{abstract}

KEYWORDS: promoter, cloning, DNA sequence, tiger prawn

\section{INTRODUCTION}

The effective construct of expression vector in transgenic technology is one of the important roles of implementing genetic transformation process in organism. Expression vector usually contains three elements, i.e. promoter, target gene, and signal of transcription termination. Among the abovementioned elements, a suitable promoter is the most important element on the successful gene transformation system because a promoter regulates when, where, in what condition, and which gene target should be activated.

Promoter is a specific DNA sequence serving as the regulator in controlling gene transcription and located at the upstream of a structural gene. Therefore, promoter has a role in the regulation of expression level of target genes (Hoare \& Beaumont, 2003). The transcription process is initially started by binding transcription factors and complex enzymes of RNA polymerase in the promoter area. As promoter plays an important role in application of transgenic technology, the choice of promoter for regulating the expression of foreign gene is a main consideration. Yazawa et al. (2005) reported that different promoters regulated the expression of GFP (green fluorescent gene) with different patterns in transgenic zebrafish.

In the first development of transgenic fish, gene constructs of promoter and target gene

\# Corresponding author. Research Institute for Coastal Aquaculture. Jl. Makmur Dg. Sitakka - Maros. Sulawesi Selatan 90511, Indonesia. Tel.: +62 411171544

E-mail address: 
were isolated from terrestrial animal and micro- organisms. Early experimental work on transgenic fish used promoter from avian (roust sarcoma virus, RSV) or primate viruses (simian virus, SV- 40; and cytomegalovirus, CMV), but recently, efforts have been done to design an 'all- fish' promoter from fish genomes rather than the genomes from other animal groups. The promoters that have been used in transgenic research of aquaculture species are salmon, trout, tilapia, catfish, and carp. The use of gene construct from terrestrial animal and microorganisms did not show significant effect on fish growth, where promoter isolated from non-fish species showed a low transgene expression or no expression. Alam et al. (1996), Hanley et al. (1998), and Alimuddin et al. (2005) have proved that promoters isolated from fish species showed a higher level of activity than that of terrestrial animal and virus. The increase of growth was obtained from the construct of promoter and growth hormone $(\mathrm{GH})$ genes isolated from fish species, known as all-fish gene construct, for instance: transgenic salmon using methallothionein promoter and salmon (Yaskowiak et al., 2006) and transgenic mud loach by promoter $\beta$ - actin and mud loach GH (Nam et al., 2001). Nile tilapia transgenic using medaka $\beta$-actin promoter and Nile GH gene also showed the growth rate of seven times higher than that of non- transgenic within one year (Kobayashi et al., 2007). According to Volckaert et al. (1994), promoter $\beta$ - actin is known as a constitutive promoter, because it is able to show activity without outside inducer such as temperature or hormones. The other promoter, $\beta$-actin, will act as ubiquitous that shows activity in all muscle tissues, or always shows activity at any time that is needed (house keeping). The promoter usually has important elements such as: CCAAT box to increase expression by specific stimulation; CC(A/T) $)_{6} \mathrm{GG}$ unit, known as CarG motif to regulate the transgene expression; and TATA box to regulate the right position of transcription process (Takagi et al., 1994). The analysis of promoter activity was usually conducted by microinjection technique of gene construct into embryo using reporter gene for GFP (green fluorescent protein) to observe the transgene expression (Takagi et al., 1994; Muller et al., 1997; Hamada et al., 1998; Alimuddin, 2003; Kobolak \& Muller, 2003; Maclean et al., 2002; Kato et al., 2007). Other methods could be conducted by direct injection to muscle of fish or by transfection into cell culture (Kato et al., 2007).
Application of transgenic on crustacean especially for shrimp species is still rare and so that promoter application. Transgenic shrimp was just reported on white shrimp Litopenaeus vannamei by introducing the gene encoding anti- virus TSV (taura syndrome virus) driven by shrimp $\beta$-actin promoter (pßactP2) (Sun et al., 2005; Lu \& Sun, 2005). Moreover, Luo et al. (2007) have isolated seven promoters from tiger prawn, but only two of them showed activities in in vitro assay by transfection into cell line using GFP as a reporter gene. Based on these results, isolation and characterization are necessary to be conducted prior to perform the activity assay of promoter. This research aims to study the similarity index of promoter sequences used in this study with the same ones kept at the GenBank. The analysis on the motif of transcription factor and specific promoter sequence was performed in order to confirm the appropriate promoter isolated from tiger prawn.

\section{MATERIAL AND METHOD}

\section{Tiger Prawn, Penaeus monodon}

Samples of tiger prawn, P. mododon (Crustacea, Decapoda) (approximately 50- 100 g) were collected from a brachkistwater pond in South Sulawesi, Indonesia. The tiger prawn were transported alive to laboratory prior to DNA extraction.

\section{DNA Extraction}

The genomic DNA of $P$. monodon was isolated from muscle tissue by phenolchloroform extraction method developed by Parenrengi et al. (2000). The genomic DNA was electrophoresed at a $0.8 \%(\mathrm{w} / \mathrm{v})$ horizontal agarose gel at 55 volts for $1-2$ hours in $1 \times$ TBE buffer (0.9 M Tris, 1.1 M Boric acid and $25 \mathrm{mM}$ EDTA at $\mathrm{pH} 8.3$ for $10 \mathrm{X}$ ) and the staining was done in $0.5 \mu \mathrm{g} / \mathrm{mL}$ of ethidium bromide for 20-30 minutes and followed by washing with distilled water for 5-10 minutes.

The purity of genomic DNA obtained was estimated by measuring in a UV- VIS Spectrophotometer. The DNA concentration and purity was quantitatively estimated from the ratio between the reading of absorbency at $260 \mathrm{~nm}$ and $280 \mathrm{~nm}\left(\mathrm{OD}_{260} / \mathrm{OD}_{280}\right)$ (Linacero et al., 1998), and DNA purity was also qualitatively observed through the appearance of a single band on the $0.7 \%$ agarose gel. 


\section{Promoter Isolation}

Promoter isolation was performed using PCR technique on the Genomic DNA extracted from muscle tissue of the tiger prawn. The method of promoter isolation is based on the technique that has been developed by Luo et al. (2007), using the primers: forward ProAV-F: 5'- gtc gga tcc agt ccc aca ctc cat caa - 3' and reverse ProAV- R: 5' - ctg gga tcc ctg aaa gga ata tta ata tct tg - 3'. Both primers were added into the restriction enzyme cutting site of BamHI (underlined sequences). Genomic DNA was a template for promoter isolation for target fragment of $368 \mathrm{bp}$. PCR reaction used the kit of PureTaq Ready-To-Go PCR Beads (GE Healthcare) with $1 \mu \mathrm{L}$ for each primer and water sterile until the final volume of $25 \mu \mathrm{L}$. PCR was processed in the 2720 Thermal Cycler (Applied Biosystems) with the following program: initial denaturation of $3 \mathrm{~min}$ at $92^{\circ} \mathrm{C}$; followed by 35 cycles of denaturation $1 \mathrm{~min}$ at $92^{\circ} \mathrm{C}$, annealing $45 \mathrm{sec}$ at $56^{\circ} \mathrm{C}$, and extension $1 \mathrm{~min} 15 \mathrm{sec}$ at $72^{\circ} \mathrm{C}$; and final extension of $5 \mathrm{~min}$ at $72^{\circ} \mathrm{C}$. To determine the success of promoter isolation, the PCR product was run at $1.0 \%$ agarose gel to visualize the single fragment obtained.

\section{Cloning and Promoter Sequences}

The promoter from PCR product was purified using the GF- 1 Gel DNA Recovery Kit (Vivantis) based on the manufacture's procedure. Purified DNA fragment was cloned into the pGEM-T Easy vector (Promega) according to the vendor's manual. The promoter on the plasmid was sequenced using automatic ABI Prism 3103-Avant Genetic Analyzer (Applied Biosystems).

\section{Data Analysis}

To determine the similarity of promoters obtained in this study, the sequences were aligned with the same promoter sequences on the GeneBank (accession number: 641258-1) using BLAST- N software(Basic Local Alignment Search Tool- Nucleotide). Analysis of sequences was conducted using GENETYX version 7 in order to obtain sequence similarity, transcription/ regulatory element, specific promoter sequences, as well as phylogenetic tree between promoters.

\section{RESULTS AND DISCUSSION}

Genomic DNA has been successfully extracted from muscle tissue of tiger prawn, P.

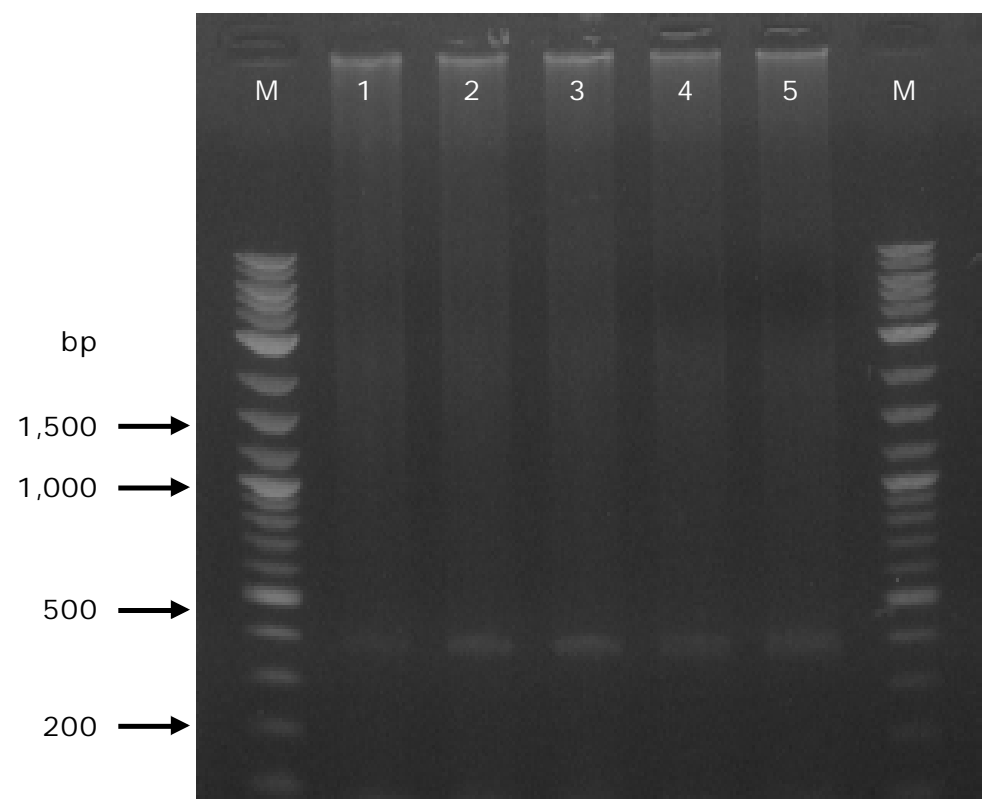

Figure 1. Single fragment of promoter isolated from genomic DNA of P. monodon. (Samples of tiger prawn (1- 5), DNA marker (M), and arrow indicating the position of promoter) 
monodon, as well as the success in isolation of ProAV promoter. The suspected promoter fragment was visualized on agarose gel by a single DNA fragment at about $0.4 \mathrm{~kb}$ (368 bp) as shown in Figure 1. To clarify the target of appropriate promoter, the purified fragment was sequenced for two random samples for further analysis.

Among 368 bp in length, the partial sequences have been performed at about 318$327 \mathrm{bp}$ in length as consensus sequences (alignment of forward and reverse sequences) Based on the nucleotide sequences obtained, the alignment sequences of two samples of promoter isolated from tiger prawn and the reference sequence of PmAV complete gene (Q641258- 1) from GeneBank is shown in Figure 2.

The result of promoter sequence alignment showed high similarity between the promoter sequences reported by Luo et al. (2007) on tiger prawn collected in China. Tabel 1 showed high similarity (95\% 98\%) among promoter sequences isolated from the samples of tiger prawn, P. monodon. The high similarity obtained from tiger shrimp in Indonesia indicates that the promoter isolated in this present study is confirmed as the ProAV promoter.

BLAST- $\mathrm{N}$ analysis showed the existence of nucleotide deletion and insertion as well as nucleotide variation with the promoter sequence from GeneBank (reference promoter). Transcription factor analysis also showed the existence of specific promoter sequences such TATAAA (popularly known as TATA- box), TGACCC (known as MRE or TFIID), and sequence of $[A / C] A[A / C] A G$ (known as TCF- 1), as the main motif that are generally identified in promoters.

On the transcription process, TATA box determines the initial transcription. Study on gene encoding histon on sea urchin showed that the deletion of TATA box, although it did not significantly decrease the efficiency of transcription, affected the specifity of initial transcription, indicating that RNA polymerase could not found the accurate place to initiate the transcription. On the other hand, the study

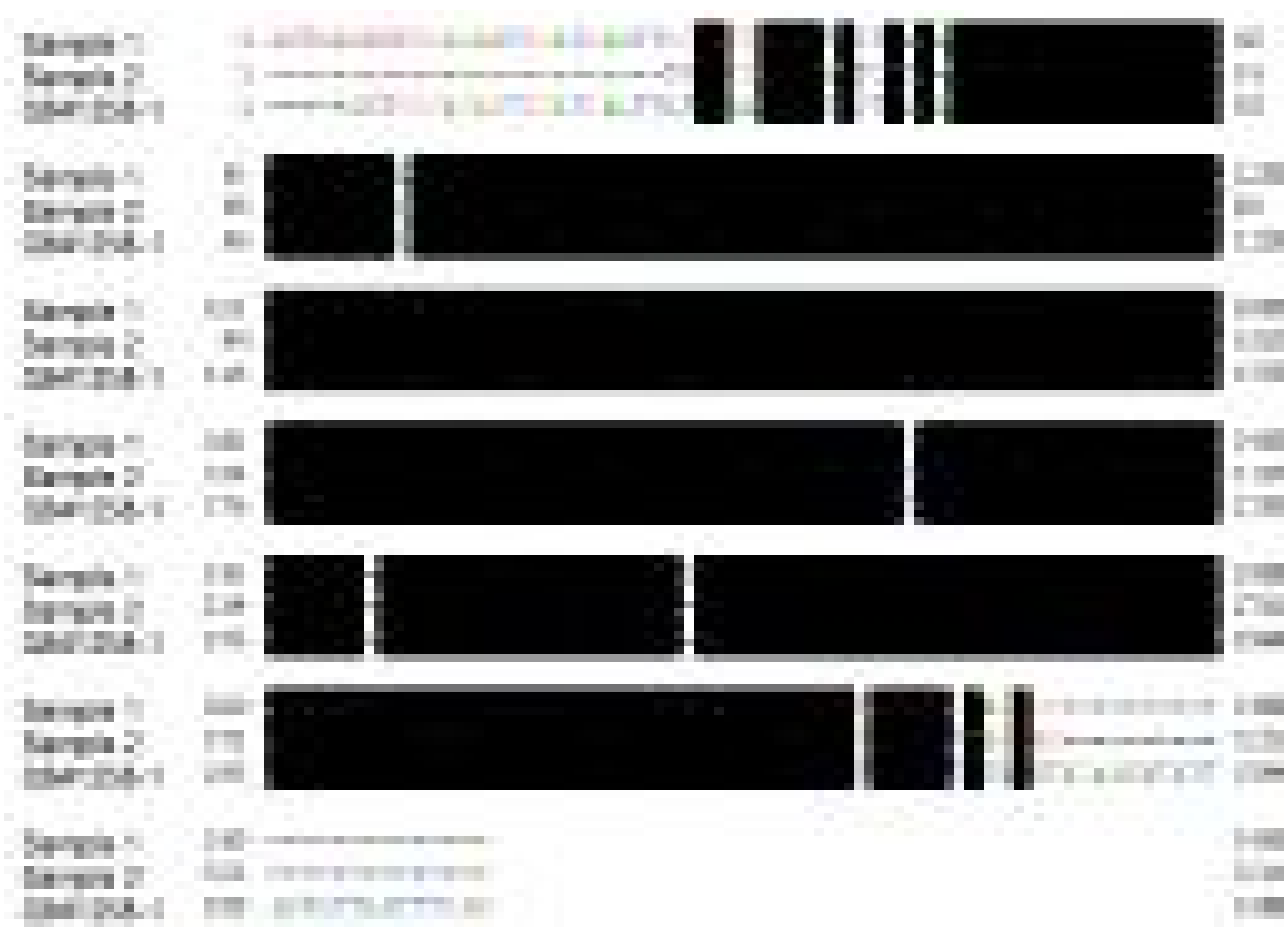

Figure 2. Sequence alignment of promoter isolated from samples of tiger prawn P. monodon with the PmAV complete gene from GeneBank at accession number of DQ6412581. (Nucleotide symbol of $A=A d e n i n e, C=C y t o s i n e, ~ G=G u a n i n e$, and $T=$ Thymine) 
Cloning of ProAV promoter isolated ... (Andi Parenrengi)

Table 1. Similarity index of promoter sequences isolated from samples of tiger prawn, P. monodon with complete gene PmAV on GeneBank at accession number of DQ641258- 1

\begin{tabular}{lcccc}
\hline Promoter & $\begin{array}{c}\text { Maximum } \\
\text { score }\end{array}$ & $\begin{array}{c}\text { Total } \\
\text { score }\end{array}$ & $\begin{array}{c}\text { Query } \\
\text { coverage }\end{array}$ & $\begin{array}{c}\text { Maximum } \\
\text { identity }\end{array}$ \\
\hline Sample 1 & 525 & 525 & $98 \%$ & $95 \%$ \\
Sample 2 & 556 & 556 & $97 \%$ & $98 \%$ \\
\hline
\end{tabular}

conducted by Benoist and Chambon in 1980 showed that the deletion of TATA box in promoter of D-globin gene on rabbit revealed that the transcription process did not showed any activity (Yuwono, 2005).

TFIID is one of the first transcription factors that is directly linked to the TATA box, so that binding of this transcription factor will guide the other transcription factors and RNA polymerase to determine the promoter region (area). The in vitro experiment has proved that a promoter without TFIID (TFIID was removed from the sequence) would not form the complex pre- initiation; however the other transcription factor was added to the promoter. Yuwono (2005) stated that TFIID transcription factor is a protein complex consisting of TATA-box binding protein (TBP) and 8-10 TAF (TBPassociated factor) or the factor transcription related to the TBF.

In the eukaryote's promoter without TATA box, TFIID binds with SP- 1 mainly bonding on the GC box, while transcription factor SP- 1 is a DNA binding domain and popularly known as a zinc finger because SP- 1 consists of zinc. The other transcription factors identified in this study is GAL- 4. As this factor transcription has a module consisting of two atom zincs and six amino acids of cysteine, GAL- 4 is known as a regulator motif involved in the regulation of GAL gene for glucose metabolism on Sacchar omyces cereviae.

The present study indicates that both ProAV promoters isolated from tiger prawn in South Sulawesi, Indonesia show a relationship with ProAV promoter isolated from tiger shrimp in China (accession number of DQ641258- 1). The phylogenetic tree of nucleotide sequence of the two promoters from Indonesia and one promoter from China is shown in Figure 3.

This preliminary study revealed the existence of important transcription factors and other potential regulatory elements as well as the high similarity of promoter sequence with the ProAV promoter obtained by Luo et al. (2007). These results indicate that the isolated promoter from tiger prawn maybe useful in transgenic technology in order to regulate the foreign gene. In the future, the study should be emphasized to confirm the promoter activity in tiger prawn embryo using the GFP as a reporter gene.

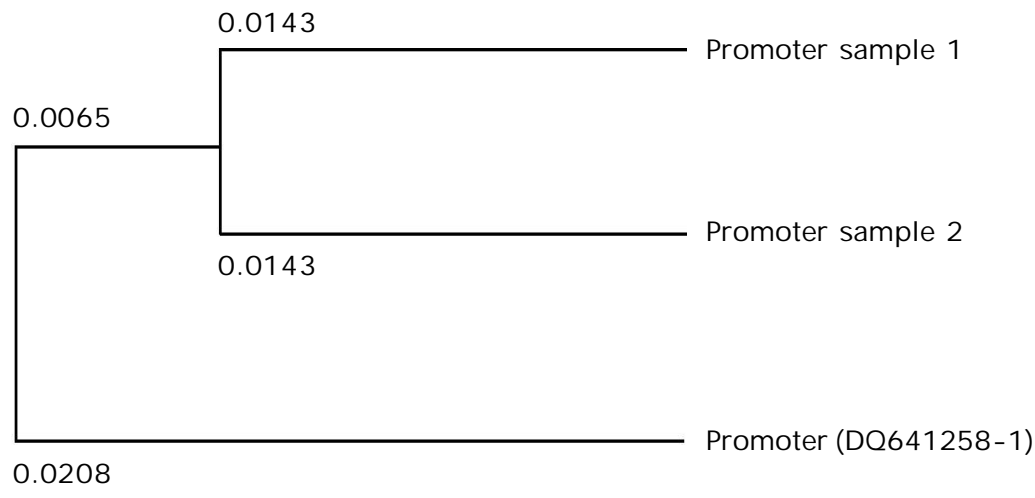

Figure 3. UPGMA dendrogram of ProAV promoter isolated from tiger prawn, P. monodon 


\section{CONCLUSION}

ProAV promoter was successfully isolated from muscle tissue of tiger prawn, P. monodon at $368 \mathrm{bp}$ in length. The promoter showed high similarity (95\% 98\%) with the same promoters in the GeneBank (accession number of DQ641258- 1). Both promoters isolated from Indonesia showed the relationship with the promoter isolated from tiger prawn in China. At least three motifs of transcription factor (TATA box, MRE, and TCF- 1 ) as well as several potential regulatory elements have been identified in promoter's sequences in this present study.

\section{REFERENCES}

Alam, M.S., Lavender, F.L., lyengar, A., Rahman, M.A, Ayad, H.H., Lathe, R., Morley, S.D., \& Maclean, N. 1996. Comparison of the activity of carp and rat â-actin gene regulatory sequences in tilapian and rainbowt trout embryos. Mol Rep Dev, 45: 117- 122.

Alimuddin. 2003. Introduction and expression of foreign "6-desaturase-like gene in a teleostean fish [thesis]. Tokyo University of Fisheries, Japan.

Alimuddin, Yoshizaki, G., Kiron, V., Satoh, S., \& Takeuchi, T. 2005. Enhancement of EPA and DHA biosynthesis by over- expression of masu salmon "6- desaturase- like gene in zebrafish. Trangenic Research, 14: 159165.

Hamada, K., Tamaki, K., Sasado, T., Watai, Y., Kani, S., Wakamatsu, Y., Ozat, o K., Kinoshita, M., Kohno, R., Takagi, S., \& Kimura, M. 1998. Usefulness of the medaka $\beta$-actin promoter investigated using a mutant GFP reporter gene in trangenic medaka (Oryzias latipes). Mol Mar Biol Biotechnol, 7(3): 173- 180.

Hanley, S., Smith, T.J., Muller, F., Maclean, N., Uzbekova, S., Prunet, P., \& Breton, B. 1998. Isolation and fuctional analysis of histone H3 promoter from Atlantic salmon (Salmo salar L.). Mol Mar Biol Biotech, 7(3): 165172.

Hoare, K. \& Beaumont, A.R. 2003. Biotechnology and genetics in fisheries and aquaculture. Blackwell Publishing Company, 158 pp.

Kato, K., Takagi, M., Tamaru, Y., Akiyama, S.I., Konishi, T., Murata, O., \& Kumai, H. 2007. Construction of an expression vector containing a $\beta$-actin promoter region for gene transfer by microinjection in red sea bream Pagrus major. Fish Sci, 73: 440- 445.

Kobolak, J. \& Muller, F. 2003. Reporter gene activities in fish embryos, In Fingerman, $M$., Nagabhushanam, editors. Recent Advances in Marine Biotechnology, Molecular Genetics of Marine Organisms, Vol. 10. Science Publishers USA, UK, p. 303326.

Kobayashi, S.I., Alimuddin, Morita, T., Miwa, M., Lu, J., Endo, M., Takeuchi, T., \& Yoshizaki, G. 2007. Transgenic nile tilapia (Oreochromis niloticus) over- expressing growth hormone showed reduced ammonia excretion. Aquaculture, 270: 427435.

Linacero, R.J., Rueda, \& Vazquez, A.M. 1998. Quantification of DNA. In Karp AP, Isaac G, Ingram DS (Eds.) Molecular Tools for Screening Biodiversity: Plants and Animals. Chapman and Hall. London, Weinheim, New York, Tokyo, Melbourne, Madras, p. 18- 21.

Lu, Y. \& Sun, P.S. 2005. Viral resistance in shrimp that express an antisense taura syndrome virus coat protein gene. Antiviral Research, 67: 141- 146.

Luo, T., Fang, L., Kaiyu, L., \& Xu, X. 2007. Genomic organization, promoter karakterization, and expression profiles of an antiviral gene PmAV from the shrimp Penaeus monodon. Molecular Immunology, 44: 1516- 1523.

Maclean, N., Rahman, M.A., Sohm, F., Hwang, G., lyengar, A., Ayad, H., Smith, A., \& Frahmand, H. 2002. Trangenic tilapia and the tilapia genome. Gene, 295: 265- 277.

Muller, F., Williams, D.W., Konolak, J., Gauvry, L., Goldspink, G., Orban, L., \& Maclean, N. 1997. Activator effect of coinjected enhancers on the muscle-specific expression of promoter in zebrafish embryos. Mol Rep Dev, 47: 404- 412.

Nam, Y.K., Noh, J.K., Cho, Y.S., Cho, H.J., Cho, K.N., Kim, C.G., \& Kim, D.S. 2001. Dramatically accelerated growth and extraordinary gigantism of transgenic mud louch Misgurnus mizolepis. Transgenic Research, 10: 353- 362.

Parenrengi, A., Shamsudin, L., Ismail, P., \& Amin, N.M. 2000. Preliminary study on DNA level marker of grouper at different buffer preservation and DNA extraction method. In Saad MS, Faridah QZ, Kadir MA., Khalid MZZ, Mohamad O, Saleh GB, Panandam JM 
(Editors). Genetic Manipulation: Challenges and Advantages. Proceeding of the $4^{\text {th }}$ National Congress on Genetics, 26- 28 Sept. 2000, Genting Highlands, Malaysia, p. 194208.

Sun, P.S., Venzon, N.C., Calderon, F.R.O., Esaki, D.M. 2005. Evaluation of methods for DNA delivery into shrimp zygotes of Penaeus (Litopenaeus) vannamei. Aquaculture, 243: 19- 26.

Takagi, S., Sasado, G., Tamiya, G., Ozato, K., Wakamatsu, Y., Takeshita, A., \& Kimura, M. 1994. An efficient expression vector for transgenic medaka construction. Mol Mar Biol Biotechnol, 3(4): 192- 199.

Volckaert, F.A., Hellemans, B.A., Galbusera, P., \& Ollevier, F. 1994. Replication, expression, and fate of foreign DNA during embryonic and larval development of the African catfish (Clarias gariepinus). Mol Mar Biol Biotechnol, 3(2): 57- 69.

Yaskowiak, E.S., Shears, M.A., Agarwal- Mawal, A., \& Fletcher, G.L. 2006. Characterization and multi-generational stability of the growth hormone transgene (EO-1á) responsible for enhanced growth rate in Atlantic salmon. Transgenic Research, 15: 465- 480.

Yazawa, R., Hirono, I., \&Aoki, T. 2005. Characterization of promoter activities of four different Japanese flounder promoters in transgenic zebrafish. Marine Biotechnology, 7: 625-633.

Yuwono, T. 2005. Molecular Biology (in Indonesian). Erlangga, Jakarta, 269 pp. 